\title{
FLORÍSTICA DA VEGETAÇÃO ARBUSTIVO-ARBÓREA COLONIZADORA DE UMA ÁreA deGrAdAdA POR MINERAÇÃo DE CAULIM, EM BRÁS PIRES, MG ${ }^{1}$
}

\author{
Fernanda Squizzatto de Araújo ${ }^{2}$, Sebastião Venâncio Martins³, João Augusto Alves Meira Neto³, \\ João Luiz Lani ${ }^{4}$ e Ismael Eleotério Pires ${ }^{3}$
}

\begin{abstract}
RESUMO - Este estudo teve como objetivos analisar a composição florística da vegetação arbustivo-arbórea colonizadora de uma área degradada por mineração de caulim, em Brás Pires, MG, compará-la com outros fragmentos florestais e caracterizar aspectos de auto-ecologia das espécies e o solo da área. O levantamento florístico abrangeu uma área de 0,5 ha, subdividida em 50 parcelas contíguas de $10 \mathrm{~m}$ x $10 \mathrm{~m}$. Foram incluídos todos os indivíduos com CAPigual ou superior a $10 \mathrm{~cm}$. A composição florística é o resultado desse levantamento acrescida de coletas fora da área de amostragem, totalizando 64 espécies, distribuídas em 50 gêneros e 30 famílias. As famílias com maior número de espécies foram Leguminosae (11), Annonaceae (5), Lauraceae e Melastomataceae (4), enquanto o gênero mais rico foi Machaerium (3). A análise do substrato, nas condições em que se encontrava, revelou que este não impedia o estabelecimento da vegetação. A síndrome de dispersão preponderante era a zoocórica, destacando-se a importância de indivíduos remanescentes, fragmentos próximos e sua fauna associada. A maior similaridade florística ocorreu com o fragmento em Cruzeiro, SP, estando ambas as áreas em início de sucessão.
\end{abstract}

Palavras-chave: Florística, restauração de áreas degradadas, mineração e regeneração natural.

\section{FLORISTIC OF SHRUB-TREE VEGETATION COLONIZING AN AREA DEGRADED BY KAOLIN MINING, IN BRÁS PIRES, MG}

\begin{abstract}
This study aimed to analyze the floristic composition of shrub-tree vegetation colonizing an area degraded by kaolin mining in Brás Pires, $M G$, compare it with other forest fragments and characterize ecological aspects of species and soil of the area. The sampled area was 0.5 ha subdivided in 50 grid plots of $10 x 10$ meters each. All individuals included had CAP equal or larger than $10 \mathrm{~cm}$. The floristic composition is the result of the sampled area plus species collected outside of it. A total of 64 species was obtained, distributed in 50 genera and 30 families. The families with the greater number of species were Leguminosae (11), Annonaceae (5), Lauraceae e Melastomataceae (4), while the richest genus was Machaerium (3). The soil analysis revealed that it had not impaired the vegetation colonization. The main dispersal syndrome was zoochorous, showing the importance of remnant individuals, surroundings forest fragments and its fauna. The greatest floristic similarity occurred in Cruzeiro, SP, being both areas at the same successional stage.
\end{abstract}

Keywords: Floristic composition, restoration of degraded areas, mining and natural regeneration.

\section{INTRODUÇÃO}

A área de terras tropicais degradadas tem aumentado nas últimas décadas devido à alta demanda de terras agricultáveis, produtos extraídos das florestas, crescimento da população humana e maior habilidade tecnológica para modificar paisagens, criando, assim, novas condições, às quais a vegetação tem que se adaptar (LUGO, 1997). Nessa perspectiva, podem-se

\footnotetext{
${ }^{1}$ Recebido em 16.09.2004 e aceito para publicação em 10.08.2005.

${ }^{2}$ Programa de Pós-Graduação em Ciência Florestal da Universidade Federal de Viçosa - UFV.

${ }^{2}$ Departamento de Engenharia Florestal da UFV. E-mail: <venancio@ufv.br>.

${ }^{3}$ Departamento de Biologia Vegetal da UFV.

${ }^{4}$ Departamento de Solos da UFV.
} 
acrescentar as atividades de mineração como fortes modificadoras da paisagem, pois degradam extensas áreas, muitas vezes de difícil recuperação, pois, além da vegetação, há degradação de solos e águas.

Atualmente, têm-se buscado alternativas para a recuperação de áreas degradadas que possibilitem a redução dos custos de recuperação e o retorno dessas áreas a uma condição ecológica mais próxima da original - a restauração ecológica. Nessa nova tendência têm sido preconizado o manejo e a indução dos processos ecológicos, com vistas a aproveitar ou estimular a resiliência do ecossistema. Para isso, o conhecimento da vegetação colonizadora das áreas degradadas, bem como aspectos relacionados às condições edáficas e à auto-ecologia das espécies, são fundamentais para a definição de metodologias de restauração (RODRIGUES e GANDOLFI, 1998).

Os estudos sobre a composição florística da comunidade colonizadora e da sucessão secundária em áreas que se encontram abandonadas depois de ter paralisado o processo de mineração são ferramentas importantes para nortear estratégias de recuperação de áreas mineradas (JOHNSON et al., 1982; BARTH, 1989; LORENZO, 1991; SKOUSEN etal., 1994; PARROTA et al., 1997). No entanto, tais estudos, abordando áreas degradadas por mineração de caulim, ainda são raros no Brasil. Dessa forma, este trabalho teve como objetivo analisar a composição florística da vegetação arbustivoarbórea colonizadora de uma área degradada por mineração de caulim, em Brás Pires, MG; sua relação com as condições edáficas locais e a comparação com outras áreas de florestas em diferentes estádios sucessionais, visando ao conhecimento da regeneração natural em áreas degradadas.

\section{MATERIAL E MÉTODOS}

\section{1. Área de Estudo}

O estudo foi desenvolvido na Fazenda Boa Esperança, situada à margem esquerda do rio Turvo, município de Brás Pires (43 10' 41' 'long. e 20 54 ' 25" lat.), distante $60 \mathrm{~km}$ de Viçosa, MG. A encosta, áreaalvo do estudo, ocupa aproximadamente 2 ha e apresenta uma declividade de $35 \%$ e altitude que varia de 825 $\mathrm{m}$ no terço superior a $745 \mathrm{~m}$ no terço inferior. Conforme a classificação de Köppen, o clima da região é Cwb, apresentando verões quentes e úmidos, com pluviosidade anual de 1.200 a $1.500 \mathrm{~mm}$, estação seca curta no inverno e temperatura média anual entre $19,5^{\circ}$ e $21,8^{\circ}$ (NATALI et al., 1997). A atividade minerária foi iniciada em 1980 e finalizada em 1985. Nos 20 anos subseqüentes, a encosta onde foi depositado o estéril, anteriormente utilizada como pastagem, foi isolada, e um processo de regeneração natural se iniciou, estando atualmente ocupada por uma vegetação florestal secundária.

\subsection{Caracterização do Substrato}

Para caracterizar o solo onde a vegetação se desenvolveu, foram amostrados três perfis ao longo da encosta. As amostras de cada horizonte foram submetidas a análises químicas e físicas, realizadas pelo Departamento de Solos da Universidade Federal de Viçosa, conforme recomendações da Embrapa (1999).

\subsection{Levantamento Florístico}

O levantamento florístico foi sistemático em uma área de 0,5 ha, dividida em 50 parcelas de $10 \mathrm{~m} \mathrm{X} 10$ $\mathrm{m}$, que também foi objeto de análise fitossociológica, e expedito, através de percursos aleatórios nas bordas e interior da floresta. Foram consideradas neste estudo as espécies que apresentaram indivíduos com perímetro a 1,30 m do solo (DAP), igual ou superior a $10 \mathrm{~cm}$. A identificação foi realizada por meio de comparação com exsicatas do herbário VIC da UFV e consultas a especialistas, quando necessário.

\subsection{Síndromes de Dispersão de Sementes}

Para a caracterização das síndromes de dispersão foram utilizados os critérios e categorias propostos por van der Pijl (1982), reunidos em três grupos básicos: espécies anemocóricas (vento), zoocóricas (animais) e autocóricas (gravidade ou deiscência explosiva). Foram utilizados como referências os estudos de Morellato e Leitão-Filho (1992), Tabarelli et al. (1994) e Carmo e Morellato (2000).

\subsection{Classificação Sucessional das Espécies}

As espécies foram agrupadas em categorias sucessionais: pioneiras, secundárias iniciais e secundárias tardias, conforme a classificação proposta por Gandolfi et al. (1995) e utilizando-se como base os trabalhos (MARTINS e RODRIGUES, 2002; MARTINS et al., 2002, 2004). Nas espécies não encontradas na literatura, a classificação baseou-se em observações de campo sobre sua ocorrência em diferentes ambientes das florestas da região. 


\subsection{Similaridade Florística}

Na comparação florística com outros remanescentes de Floresta Estacional Semidecidual foram reunidos 10 trabalhos com florística em diferentes estádios sucessionais, incluindo este. A partir de uma matriz de dados binários (presença e ausência) das espécies das 10 áreas, produziu-se uma matriz de coeficientes de similaridade de Jaccard. Para interpretar as similaridades florísticas entre as áreas, empregou-se uma análise de agrupamento, pelo método média de grupo (UPGMA) (VALENTIM, 2000). Todas as análises foram realizadas com o programa FITOPAC (SHEPHERD, 1996). A validação dos nomes das espécies foi feita utilizando a base de dados fornecida pelo Missouri Botanical Garden (www.mobot.org).

\section{RESULTADOS E DISCUSSÃO}

\subsection{Análise do Substrato}

O solo da área foi caracterizado como Latossolo Vermelho-Amarelo distrófico, sendo o horizonte Bw pouco espesso. No topo da encosta, percebe-se a exposição do horizonte $\mathrm{C}$, devido à intensa erosão. Ao longo da encosta, pela deposição do estéril sobre o solo original, desenvolveu-se novo horizonte A pouco espesso, advindo da vegetação. Nos três perfis amostrados há uma diferenciação clara entre o material de origem do solo (horizonte $\mathrm{C}$ ), a camada de estéril e o solo original (enterrado).

A camada de estéril mostrou profundidade variável $(0$ a $25 \mathrm{~cm})$ sobre a qual se percebe o desenvolvimento de um horizonte $\mathrm{A}(0 \mathrm{a} 2 \mathrm{~cm})$. Esse horizonte pode estar relacionado com a abundância de espécies pioneiras na área, favorecendo a maior produção de serapilheira e, conseqüentemente, a maior incorporação de matéria orgânica no solo. Isso foi constatado em clareiras de uma Floresta Estacional Semidecidual de Campinas, $\mathrm{SP}$, onde a produção de serapilheira foi relacionada com a dominância de pioneiras (MARTINS e RODRIGUES, 2002). Em estudo realizado em área de mineração de bauxita na Amazônia, a ação da matéria orgânica é apontada como responsável pelo sucesso da revegetação da área (PARROTA et al., 1997). Já que a matéria orgânica do solo é a principal fonte de nutrientes minerais para as plantas (FRANCO et al., 1992), a incorporação de matéria orgânica proveniente da serapilheira depositada indica ser a fonte nutricional para a manutenção da vegetação sobre a camada de estéril.

A textura da camada de depósito (perfil 2) e do horizonte $C$ (perfis 2 e 3 ) é bem arenosa, variando na quantidade de areias fina, grossa e silte (Quadro 1). Aliado a isso, esse material se apresenta muito friável, o que facilita os processos erosivos, determinando áreas com erosões variáveis, de laminares até voçorocas, presentes no interior da floresta. Entretanto, essa condição, de maior friabilidade, pode estar favorecendo o estabelecimento da vegetação, por facilitar a germinação e o desenvolvimento vegetal. Resultado semelhante foi encontrado por Teixeira e Filho (2002), em área de mineração de ferro, onde o aumento do porte das plantas foi relacionado ao incremento da friabilidade dos solos.

Uma textura mais argilosa foi encontrada apenas nos horizontes do solo soterrado (A e Bw, perfil 2), refletindo sua estrutura anterior ao depósito de estéril.

Quadro 1 - Resultados das análises físicas da área degradada por mineração de caulim, em Brás Pires, MG Table 1 -Results of the physical analysis of the area degraded by Kaolin mining in Brás Pires, MG, Brazil

\begin{tabular}{|c|c|c|c|c|c|c|c|}
\hline \multirow[t]{3}{*}{ Variáveis Físicas } & \multicolumn{7}{|c|}{ Perfis/horizontes } \\
\hline & \multirow{2}{*}{$\frac{\mathrm{P} 1}{\mathrm{C}}$} & \multicolumn{4}{|c|}{$\mathrm{P} 2$} & \multicolumn{2}{|c|}{ P3 } \\
\hline & & Ad & $\mathrm{d}$ & A & $\mathrm{Bw}$ & A & $\mathrm{C}$ \\
\hline Profundidade $(\mathrm{cm})$ & $0-5+$ & $0-2$ & $0-20$ & $20-25$ & $25+$ & $0-10$ & $40-60$ \\
\hline Areia grossa (dag/kg) & 35 & 45 & 48 & 41 & 39 & 47 & 54 \\
\hline Areia fina (dag/kg) & 30 & 9 & 8 & 6 & 7 & 12 & 18 \\
\hline Silte $(\mathrm{dag} / \mathrm{kg})$ & 33 & 27 & 27 & 18 & 16 & 22 & 14 \\
\hline Argila (dag/kg) & 2 & 19 & 17 & 35 & 38 & 19 & 14 \\
\hline Classe textural & $\begin{array}{l}\text { Franco- } \\
\text { arenosa }\end{array}$ & $\begin{array}{l}\text { Franco- } \\
\text { arenosa }\end{array}$ & $\begin{array}{l}\text { Franco- } \\
\text { arenosa }\end{array}$ & $\begin{array}{l}\text { Argilo- } \\
\text { arenosa }\end{array}$ & $\begin{array}{l}\text { Argilo- } \\
\text { arenosa }\end{array}$ & $\begin{array}{l}\text { Franco- } \\
\text { arenosa }\end{array}$ & $\begin{array}{l}\text { Franco- } \\
\text { arenosa }\end{array}$ \\
\hline
\end{tabular}

$\mathrm{P}=$ perfil, $\mathrm{C}=$ horizonte remanescente da rocha, $\mathrm{Ad}=$ horizonte $\mathrm{A}$ do depósito, $\mathrm{d}=$ camada do depósito - estéril, $\mathrm{BW}=$ horizonte latossólico e A = horizonte A original. 
Os resultados das análises químicas estão sumarizados no Quadro 2. O pH das amostras caracteriza um solo de acidez elevada à média (ALVAREZ V. et al., 1999).

Existe um dissenso quanto à influência do $\mathrm{pH}$ no estabelecimento vegetal em áreas mineradas. Enquanto Parrotta et al. (1997) e Ruivo et al. (2001) citaram que a elevada acidez não é um fator limitante, Jhonson et al. (1982) afirmavam que o estabelecimento espontâneo da vegetação em superfícies mineradas ocorreu de acordo com a idade dos sítios e com as diferenças nas propriedades dos solos, principalmente $\mathrm{pH}$ e elementos tóxicos. Skousen et al. (1994), comparando sítios com diferentes valores de acidez, constataram diferença significativa na colonização vegetal em função do $\mathrm{pH}$. Portanto, é sugerido que outros fatores, atuando isoladamente ou em conjunto com esse caráter, sejam mais decisivos na colonização vegetal.

A capacidade de troca catiônica efetiva foi considerada baixa em todas as camadas, exceto no horizonte A do depósito no Perfil 2, onde foi considerado bom (ALVAREZV. et al., 1999). O maior valor em saturação de alumínio foi encontrado no terço superior no perfil 1. A camada mais superficial $(0-2 \mathrm{~cm})$, onde se formou o horizonte A da camada de estéril, apresentou os maiores valores para a maioria das variáveis medidas, sendo os valores encontrados nas outras camadas mais baixas. Com isso, pode-se inferir que a vegetação consegue retirar nutrientes das camadas mais profundas e depositar nas camadas superficiais, evidenciando o papel da ciclagem de nutrientes nesse sistema.

\subsection{Levantamento Florístico}

O levantamento florístico totalizou 64 espécies, distribuídas em 50 gêneros e 30 famílias. Uma morfoespécie foi identificada apenas em nível genérico e uma em nível de família (Quadro 3).

A família mais rica foi Leguminosae, com 11 espécies (Papilionoideae com 6, Mimosoideae com 3 e Caesalpinioideae com 2), seguida de Annonaceae com cinco e Lauraceae e Melastomataceae com quatro espécies cada. Asteraceae e Bignoniaceae contaram com três espécies, e Monimiaceae, Moraceae, Cecropiaceae, Erythroxylaceae, Myrtaceae e Piperaceae foram representadas por duas e as demais, por apenas uma espécie.

Machaerium foi o gênero mais rico, com três espécies. Cecropia, Xylopia, Solanum, Jacaranda, Miconia, Dalbergia, Erythroxylum, Siparuna, Ficus, Rollinia e Ocotea apresentaram duas espécies cada, enquanto os 38 restantes exibiram somente uma.

Quadro 2 - Resultados das análises químicas da área degradada por mineração de caulim, em Brás Pires, MG Table 2 - Rresults of the chemical analysis of the area degraded by Kaolin mining in Brás Pires, MG, Brazil

\begin{tabular}{|c|c|c|c|c|c|c|c|}
\hline \multirow[t]{4}{*}{ Variáveis Químicas } & \multicolumn{7}{|c|}{ Perfis/Horizontes } \\
\hline & \multirow{3}{*}{$\begin{array}{c}\mathrm{P} 1 \\
\text { Terço Superior } \\
\mathrm{C} \\
\end{array}$} & \multirow{2}{*}{\multicolumn{4}{|c|}{$\begin{array}{c}\mathrm{P} 2 \\
\text { Terço Médio }\end{array}$}} & \multirow{2}{*}{\multicolumn{2}{|c|}{$\begin{array}{c}\text { P3 } \\
\text { Terço Inferior }\end{array}$}} \\
\hline & & & & & & & \\
\hline & & Ad & $\mathrm{d}$ & $\mathrm{A}$ & $\mathrm{Bw}$ & A & $\mathrm{C}$ \\
\hline pH (H2O) & 5,18 & 5,38 & 5,05 & 5,01 & 4,96 & 5,71 & 5,41 \\
\hline $\mathrm{P}\left(\mathrm{mg} / \mathrm{dm}^{3}\right)$ & 3,90 & 3,70 & 0,20 & 0 & 0 & 2,10 & 0,20 \\
\hline P-rem (mg/1) & 39,8 & 54,00 & 43,6 & 29,3 & 46,20 & 47,00 & 41,3 \\
\hline $\mathrm{K}\left(\mathrm{mg} / \mathrm{dm}^{3}\right)$ & 3,00 & 61,00 & 5,00 & 7,00 & 3,00 & 51,00 & 13,00 \\
\hline $\mathrm{Ca}^{2+}\left(\mathrm{cmol} / \mathrm{dm}^{3}\right)$ & 0,07 & 4,19 & 0,11 & 0,02 & 0,07 & 1,29 & 1,08 \\
\hline $\mathrm{Mg}^{2+}\left(\mathrm{cmol} / \mathrm{dm}^{3}\right)$ & 0,06 & 1,39 & 0,19 & 0,18 & 0,13 & 0,63 & 0,49 \\
\hline $\mathrm{Al}^{+3}\left(\mathrm{cmol} / \mathrm{dm}^{3}\right)$ & 0,80 & 0,10 & 0,7 & 0,80 & 0,90 & 0,10 & 0,10 \\
\hline $\mathrm{H}+\mathrm{Al}\left(\mathrm{cmol} / \mathrm{dm}^{3}\right)$ & 2,60 & 6,80 & 3,30 & 4,60 & 3,60 & 5,10 & 3,00 \\
\hline $\mathrm{SB}\left(\mathrm{cmol} / \mathrm{dm}^{3}\right)$ & 0,14 & 5,74 & 0,31 & 0,22 & 0,21 & 2,05 & 1,60 \\
\hline $\mathrm{t}\left(\mathrm{cmol} / \mathrm{dm}^{3}\right)$ & 0,94 & 5,84 & 1,01 & 1,02 & 1,11 & 2,15 & 1,70 \\
\hline $\mathrm{T}\left(\mathrm{cmol} / \mathrm{dm}^{3}\right)$ & 2,74 & 12,54 & 3,61 & 4,82 & 3,81 & 7,15 & 4,60 \\
\hline $\mathrm{V}(\%)$ & 5,10 & 45,80 & 8,60 & 4,60 & 5,50 & 28,70 & 34,8 \\
\hline $\mathrm{m}(\%)$ & 85,1 & 1,70 & 69,3 & 78,4 & 81,1 & 4,70 & 5,90 \\
\hline MO (dag/kg) & 6,38 & 12,36 & 6,38 & 7,12 & 6,85 & 7,93 & 6,65 \\
\hline
\end{tabular}

$\mathrm{P}=$ perfil, $\mathrm{C}=$ horizonte remanescente da rocha, $\mathrm{Ad}=$ horizonte $\mathrm{A}$ do depósito, $\mathrm{d}=$ camada do depósito - estéril, $\mathrm{BW}=$ horizonte latossólico e $\mathrm{A}=$ horizonte A original.

R. Árvore, Viçosa-MG, v.29, n.6, p.983-992, 2005 
Quadro 3 - Lista florística das espécies amostradas em área degradada por mineração de caulim, em Brás Pires, MG, apresentada por ordem alfabética de famílias e gêneros. CS: Categorias sucessionais $(\mathrm{P}=$ pioneira, $\mathrm{SI}=$ secundária inicial, $\mathrm{ST}=$ secundária tardia, SC = sem classificação), SD: Síndrome de dispersão de sementes $(\mathrm{ZOO}=$ zoocórica, $\mathrm{ANE}=$ anemocórica AUT $=$ autocórica e DESC $=$ desconhecida)

Table 3 - Floristic list of species sampled in an area degraded by Kaolin mining, in Brás Pires, MG, Brazil, presented in alphabetical order of families and genera. CS: succecional categories $(P=$ pioneer species, $S I=$ initial secondary species, $S T$ = late secondary species, $S C=$ non classified); $S D$ : dispersal syndrome of seeds $(Z O O=$ zoochorous, $A N E=$ anemochorous, AUT $=$ autochorous)

\begin{tabular}{|c|c|c|}
\hline Famílias/Espécies & CS & $\mathrm{SD}$ \\
\hline $\begin{array}{l}\text { ANACARDIACEAE } \\
\text { Schinus terebinthifolius Raddi } \\
\text { ANNONACEAE }\end{array}$ & $\mathrm{P}$ & $\mathrm{ZOO}$ \\
\hline Annona cacans Warm. & SI & $\mathrm{ZOO}$ \\
\hline Rollinia laurifolia Schlecht. & SI & $\mathrm{ZOO}$ \\
\hline Rollinia sylvatica Mart. & SI & $\mathrm{ZOO}$ \\
\hline Xylopia brasiliensis Sprengel & SI & $\mathrm{ZOO}$ \\
\hline $\begin{array}{l}\text { Xylopia sericea St. Hill. } \\
\text { ARECACEAE }\end{array}$ & SI & $\mathrm{ZOO}$ \\
\hline $\begin{array}{l}\text { Syagrus romanzoffiana (Cham.) Glassman } \\
\text { ASTERACEAE }\end{array}$ & SI & $\mathrm{ZOO}$ \\
\hline Piptocharpha macropoda Baker & $\mathrm{P}$ & ANE \\
\hline Vernonanthura diffusa (Less.) M. Robinson & $\mathrm{P}$ & ANE \\
\hline $\begin{array}{l}\text { Indeterminada } 1 \\
\text { BIGNONIACEAE }\end{array}$ & $\mathrm{P}$ & DESC \\
\hline Jacaranda micrantha Cham. & $\mathrm{P}$ & ANE \\
\hline $\begin{array}{l}\text { Jacaranda puberula Cham. } \\
\text { Sparatosperma leucantum K. Schum } \\
\text { CECROPIACEAE }\end{array}$ & $\begin{array}{l}\text { SI } \\
\text { SI }\end{array}$ & ANE \\
\hline Cecropia hololeuca $\mathrm{Miq}$ & $\mathrm{P}$ & $\mathrm{ZOO}$ \\
\hline $\begin{array}{l}\text { Cecropia glaziovi Snethlage } \\
\text { CLUSIACEAE }\end{array}$ & $\mathrm{P}$ & $\mathrm{ZOO}$ \\
\hline $\begin{array}{l}\text { Vismia magnoliaefolia Cham. Schlecht. } \\
\text { COMBRETACEAE }\end{array}$ & $\mathrm{P}$ & DESC \\
\hline $\begin{array}{l}\text { Terminalia brasiliensis } \\
\text { (Cambess. ex A. St.Hill.) Eichler. } \\
\text { ELAECARPACEAE }\end{array}$ & $\mathrm{SC}$ & ANE \\
\hline $\begin{array}{l}\text { Sloanea monosperma Vell. } \\
\text { ERYTHROXYLACEAE }\end{array}$ & $\mathrm{SC}$ & $\mathrm{ZOO}$ \\
\hline Eryhtroxylum pelleterianumSt. Hill. & SI & $\mathrm{ZOO}$ \\
\hline $\begin{array}{l}\text { Eryhtroxylum cf. citrifolium St. Hill. } \\
\text { EUPHORBIACEAE }\end{array}$ & $\mathrm{SC}$ & $\mathrm{ZOO}$ \\
\hline Hyeronima alchorneoides Fr. Allem. & SI & $\mathrm{ZOO}$ \\
\hline Mabea fistulifera Mart. & $\mathrm{P}$ & AUT/ZOO \\
\hline Manihot pilosa Pohl & $\mathrm{P}$ & DESC \\
\hline $\begin{array}{l}\text { Sapium glandulosum (Vell.) Pax } \\
\text { FLACOURTIACEAE }\end{array}$ & $\mathrm{P}$ & ZOO/AUT \\
\hline $\begin{array}{l}\text { Casearia sylvestris Swartz } \\
\text { LACISTEMATACEAE }\end{array}$ & $\mathrm{P}$ & $\mathrm{ZOO}$ \\
\hline $\begin{array}{l}\text { Lacistema pubescens Mart. } \\
\text { LAURACEAE }\end{array}$ & SI & DESC \\
\hline Nectandra opositifolia Ness & $\mathrm{SC}$ & $\mathrm{ZOO}$ \\
\hline Ocotea cf. diospyrifolia (Meisn.) Mez & SI & $\mathrm{ZOO}$ \\
\hline Ocotea corymbosa (Meisn.) Mez & $\mathrm{SC}$ & $\mathrm{ZOO}$ \\
\hline
\end{tabular}

Quadro 3 - Cont.

Table 3-Cont.

\begin{tabular}{lcc}
\hline Persea sp. & SI & ZOO \\
\hline LEGUMINOSAE Caesalpinioideae & & \\
$\begin{array}{l}\text { Copaifera langsdorffi Desf. } \\
\text { Senna macranthera (DC. Ex Collad.) }\end{array}$ & SI & ZOO \\
$\begin{array}{l}\text { Irwin \& Barneby } \\
\text { Famílias/Espécies }\end{array}$ & AUT \\
LEGUMINOSAE Mimosoideae & & SD \\
$\begin{array}{l}\text { Anadenanthera peregrina } \text { (L.) Speg. } \\
\text { Piptadenia gonoacantha Mart. }\end{array}$ & SI & ANE \\
Pseudopiptadenia contorta (DC.) & SI & ANE \\
& SI & ANE
\end{tabular}

Pseudopiptadenia contorta (DC.)

ANE

Lewis \& Lima

LEGUMINOSAE Papilionoideae

Dalbergia nigra (Vell.) Allem.

Dalbergia variabilis Vogel

Machaerium brasiliensis Vog

Machaerium nyctitans (Vell.) Benth.

Machaerium stipitatum Vog

Platypodium elegans Vog

MELASTOMATACEAE

Leandra niangaeformis Cogn.

Miconia albicans (Sw.) Triana

Miconia cinnamomifolia (DC.) Naudin

Tibouchina granulosa (Desr.) Cogn.

MELIACEAE

Cedrela fissilis Vell.

MONIMIACEAE

Siparuna guianensis Aublet

Siparuna minutiflora Perk

MORACEAE

Ficus guaranitica Chodat

Ficus enormis (Mart. ex Miq.) Mart.

MYRSINACEAE

Myrsine ferruginea (Mart.) Mez. $\quad$ SI $\quad$ ZOO

MYRTACEAE

Myrcia fallax (Richard) DC.

Psidium rufum DC.

PIPERACEAE

Ottonia $c f$. propinqua Miq.

Piper sp.

RUBIACEAE

Coutarea hexandra (Jack.) K. Schum. ST ZOO

RUTACEAE

Zanthoxylum rhoifolium Lam.

$\mathrm{ZOO}$

SAPIDANCEAE

Matayba eleagnoides Radlk.

SI

ZOO

SOLANACEAE

Brunfelsia brasiliensis (Spreng.) L. B. SI ZOO

SM. \& Downs

Cestrum coriaceum Miers $\quad$ SC ZOO

Solanum cernum Vell.

$\mathrm{ZOO}$

Solanum swartzianum Roem. \& Schult. P $\quad$ ZOO

TILIACEAE

Luehea grandiflora Mart.

ANE

ULMACEAE

Trema micrantha Blume 
Em trabalhos desenvolvidos na região de Viçosa, constatou-se que as famílias com maior número de espécies foram Leguminosae (Caesalpinioideae, Mimosoideae e Papilionoideae), Myrtaceae, Rubiaceae, Lauraceae e Euphorbiaceae (PAULA et al., 2002; MEIRA NETO e MARTINS, 2002; IRSIGLER, 2002; MARANGON et al., 2003; RIBAS et al., 2003; SILVA et al., 2003). Resultados semelhantes foram encontrados por Leitão-Filho (1982) em Florestas Semideciduais no Estado de São Paulo, onde se destaca a riqueza das famílias Leguminosae, Myrtaceae, Lauraceae e Rubiaceae. Em outras Florestas Estacionais Semideciduais na região sudoeste de Minas Gerais, OliveiraFilhoe Machado(1993)e Oliveira-Filhoetal.(1994) relataram as famílias mais ricas como sendo Leguminosae, Lauraceae, Myrtaceae, Euphorbiaceae e Annonaceae. Apesar de esse padrão se estender dentro dessa tipologia florestal, existe uma variação na ordem de riqueza entre famílias nas diferentes áreas estudadas, diferindo de acordo com características ambientais e do histórico de uso de cada ambiente.

A área já apresenta composição florística diversificada, com uma riqueza aparente considerando o atual estádio do processo de regeneração natural. Colabora para o desenvolvimento da vegetação a proximidade com fragmentos de floresta secundária, com efetiva dispersão de sementes. Tal evento possui papel determinante na riqueza da regeneração em áreas de mineração de bauxita na Amazônia (PARROTA et al., 1997) e no Mato Grosso (RODRIGUES et al., 2004), confirmando a importância da conservação de fragmentos florestais remanescentes para a restauração de áreas degradadas.

\subsection{Síndromes de Dispersão de Sementes}

A principal síndrome de dispersão é a zoocórica, observada em mais de $60 \%$ das espécies que se encontram na área. A anemocoria contribui com $33 \%$, enquanto as $7 \%$ restantes são autocóricas ou desconhecidas.

A fauna exerce função essencial na dispersão de sementes de remanescentes próximos, contribuindo para a regeneração florestal em áreas degradadas (PARROTA etal., 1997; WUNDERLEJr., 1997; MEDELLÍN eGAONA, 1999). A proximidade de fragmentos florestais e a presença de dois indivíduos de grande porte de Piptadenia gonoacantha e dois de Anadenanthera peregrina remanescentes certamente contribuíram para estimular a ornitocoria e a quiropterocoria na área estudada. Árvores remanescentes em paisagens degradadas funcionam como locais de pouso durante o deslocamento de pássaros entre fragmentos do entorno, podendo contribuir para a sucessão secundária nessas áreas (GUEVARA et al., 1986).

\subsection{Classificação Sucessional das Espécies}

$\mathrm{Na}$ distribuição das espécies em categorias sucessionais, as secundárias inicias ocuparam a primeira posição, seguida das pioneiras, perfazendo juntas $80 \%$ do total das espécies amostradas (Figura 1); as espécies secundárias tardias contribuíram com baixos valores. A maior riqueza de espécies secundárias iniciais caracterizam uma fase de transição da floresta pioneira. As novas condições ecológicas, especialmente sombreamento, favorecem o estabelecimento de espécies secundárias tardias, caracterizando um típico modelo de facilitação (CONNELLe SLATYER, 1977). Nesse sentido, a família Leguminosae, a mais rica neste estudo, possui papel singular na recuperação de áreas degradadas. Essa família agrega características importantes na ativação e regulação dos recursos disponíveis, permitindo o surgimento de espécies mais exigentes (CAMPELLO, 1998). Tal efeito ajuda a explicar a presença de espécies típicas de estádios sucessionais mais avançados na área de estudo, apesar da degradação a que foi submetida.

\subsection{Similaridade Florística}

Os trabalhos utilizados para a comparação são apresentados no Quadro 4. As relações florísticas são visualizadas nos dendrogramas gerados pelo método Média de Grupo (UPGMA) (Figura 2), respectivamente. A análise gráfica indica a formação de três grupos distintos, que se ligam com um baixo índice de similaridade, destacando a baixa semelhança florística entre as áreas (MUELLERDOMBOIS E ELLENBERG, 1974).

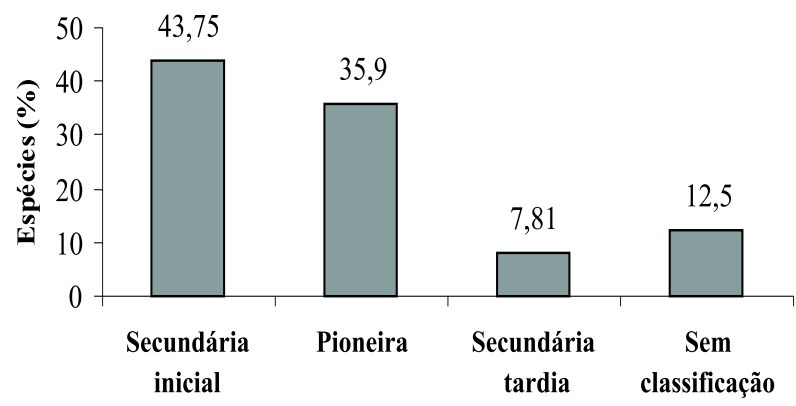

Figura 1 - Distribuição das espécies amostradas em área degradada por mineração de caulim, em Brás Pires, MG, em categorias sucessionais.

Figure 1-Distribution of the species sampled in area degraded by kaolin mining, in Brás Pires, MG, Brazil, in succecional categories. 
Quadro 4 - Características ambientais e ecológicas e métodos de amostragem das 10 áreas utilizadas para a determinação da similaridade florística: número de espécies encontradas (Nsp); índice de diversidade (H'); método utilizado e esforço amostral (MET); critério de inclusão em cm (CRIT); altitude em m (ALT); e pluviosidade em mm (PLUV)

Table 4 - Environmental, ecological characteristics and methods of sampling of the 10 areas used for the determination of the floristic similarity: number of found species (Nsp); diversity index $\left(H^{\prime}\right)$; methodology (MET); inclusion criterion in cm (CRIT); altitude in m (ALT); rainfall in mm (PLUV)

\begin{tabular}{|c|c|c|c|c|c|c|c|c|c|}
\hline$\underline{\text { Local }}$ & $\mathrm{Nsp}$ & $\mathrm{H}^{\prime}$ & MET & CRIT & ALT & PLUV & Local & Situação ecológica & Fonte \\
\hline $\mathrm{A}$ & 64 & 2,75 & $\begin{array}{c}\text { Parcelas } \\
0,5 \text { ha }\end{array}$ & $\mathrm{CAP}>=10$ & 784 a 825 & $\begin{array}{c}1200 \mathrm{a} \\
1500\end{array}$ & $\begin{array}{l}\text { Fazenda Boa Esperança } \\
\text { (Brás Pires/MG) }\end{array}$ & $\begin{array}{l}\text { Regeneração natural em área de estéril de caulim } \\
\text { (sobre pastagem), } 20 \text { anos }\end{array}$ & Este trabalho \\
\hline B & 233 & 4,44 & $\begin{array}{l}\text { Parcelas } \\
1 \text { ha }\end{array}$ & $\mathrm{CAP}>=10$ & 650 a 800 & 1221,4 & $\begin{array}{l}\text { Fazenda Bom Sucesso } \\
\text { (Viçosa/MG) }\end{array}$ & Mata primitiva (Floresta madura) & $\begin{array}{l}\text { Irsigler } \\
\text { (2002) }\end{array}$ \\
\hline $\mathrm{C}$ & 67 & & $\begin{array}{c}\text { Parcelas } \\
0,2 \text { ha }\end{array}$ & $\mathrm{CAP}>=05$ & 650 a 800 & 1221,4 & $\begin{array}{l}\text { Sítio Palmital } \\
\text { (Viçosa/MG) }\end{array}$ & $\begin{array}{l}\text { Regeneração natural, cultura de café abandonada } \\
\text { há } 30 \text { anos submetida a corte e queima há } 15 \text { anos }\end{array}$ & $\begin{array}{l}\text { Ribas et al. } \\
\text { (2003) }\end{array}$ \\
\hline D & 69 & & $\begin{array}{c}\text { Parcelas } \\
0,2 \text { ha }\end{array}$ & $\mathrm{CAP}>=05$ & 650 a 800 & 1221,4 & $\begin{array}{l}\text { Sítio Palmital } \\
\text { (Viçosa/MG) }\end{array}$ & $\begin{array}{l}\text { Regeneração natural, cultura de café abandonada } \\
\text { há } 30 \text { anos }\end{array}$ & $\begin{array}{c}\text { Ribas et al. } \\
\text { (2003) }\end{array}$ \\
\hline E & 154 & & $\begin{array}{l}\text { Parcelas } \\
1 \text { ha }\end{array}$ & $\mathrm{CAP}>=10$ & 651 a 800 & 1221,4 & $\begin{array}{l}\text { Mata da Silvicultura } \\
\text { (Viçosa/MG) }\end{array}$ & Regeneração natural em estádio avançado, 60 anos & $\begin{array}{r}\text { Meira Neto e } \\
\text { Martins (2002) }\end{array}$ \\
\hline $\mathrm{F}$ & 197 & & $\begin{array}{l}\text { Coletas } \\
\text { aleatórias }\end{array}$ & & 652 a 800 & 1221,4 & $\begin{array}{l}\text { Mata da Pedreira } \\
\text { (Viçosa/MG) }\end{array}$ & $\begin{array}{l}\text { Regeneração natural em área de uso agrícola e } \\
\text { pedreira, abandonada há } 40 \text { anos }\end{array}$ & $\begin{array}{l}\text { Marangon et al. } \\
\text { (2003) }\end{array}$ \\
\hline G & 94 & & $\begin{array}{l}\text { Parcelas } \\
1 \text { ha }\end{array}$ & $\mathrm{CAP}>=05$ & 653 a 800 & 1221,4 & $\begin{array}{l}\text { Mata da Biologia } \\
\text { (Viçosa/MG) }\end{array}$ & $\begin{array}{l}\text { Regeneração natural, cultura de café abandonada } \\
\text { há } 78 \text { anos }\end{array}$ & $\begin{array}{l}\text { Paula et al. } \\
\text { (2002) }\end{array}$ \\
\hline $\mathrm{H}$ & 123 & & $\begin{array}{l}\text { Quadrante } \\
158 \text { pontos }\end{array}$ & $\mathrm{CAP}>=15$ & 654 a 800 & 1248 & $\begin{array}{l}\text { Fazenda São Geraldo } \\
\text { (Viçosa/MG) }\end{array}$ & $\begin{array}{l}\text { Mata preservada há } 30 \text { anos, sem histórico de } \\
\text { uso anterior }\end{array}$ & $\begin{array}{l}\text { Silva et al. } \\
\text { (2003) }\end{array}$ \\
\hline I & 89 & 3,07 & $\begin{array}{l}\text { Quadrante } \\
100 \text { pontos }\end{array}$ & $\mathrm{CAP}>=15$ & 655 a 800 & & $\begin{array}{l}\text { Hidrelétrica de Pilar } \\
\text { (Ponte Nova/MG) }\end{array}$ & $\begin{array}{l}\text { Mata em estádio avançado de sucessão } \\
\text { secundária. sem histórico de uso anterior }\end{array}$ & $\begin{array}{l}\text { Meira Neto et al. } \\
\text { (1997) }\end{array}$ \\
\hline $\mathrm{J}$ & 66 & 3,39 & $\begin{array}{l}\text { Parcelas } \\
0,6 \text { ha }\end{array}$ & $\mathrm{CAP}>=15$ & 656 a 800 & 1500 & $\begin{array}{l}\text { Vale do Paraíba } \\
\text { (Cruzeiro/SP) }\end{array}$ & $\begin{array}{l}\text { Regeneração natural em área de pastagem } \\
\text { abandonada há } 30 \text { anos }\end{array}$ & $\begin{array}{c}\text { Martins et al. } \\
\text { (2002) }\end{array}$ \\
\hline
\end{tabular}
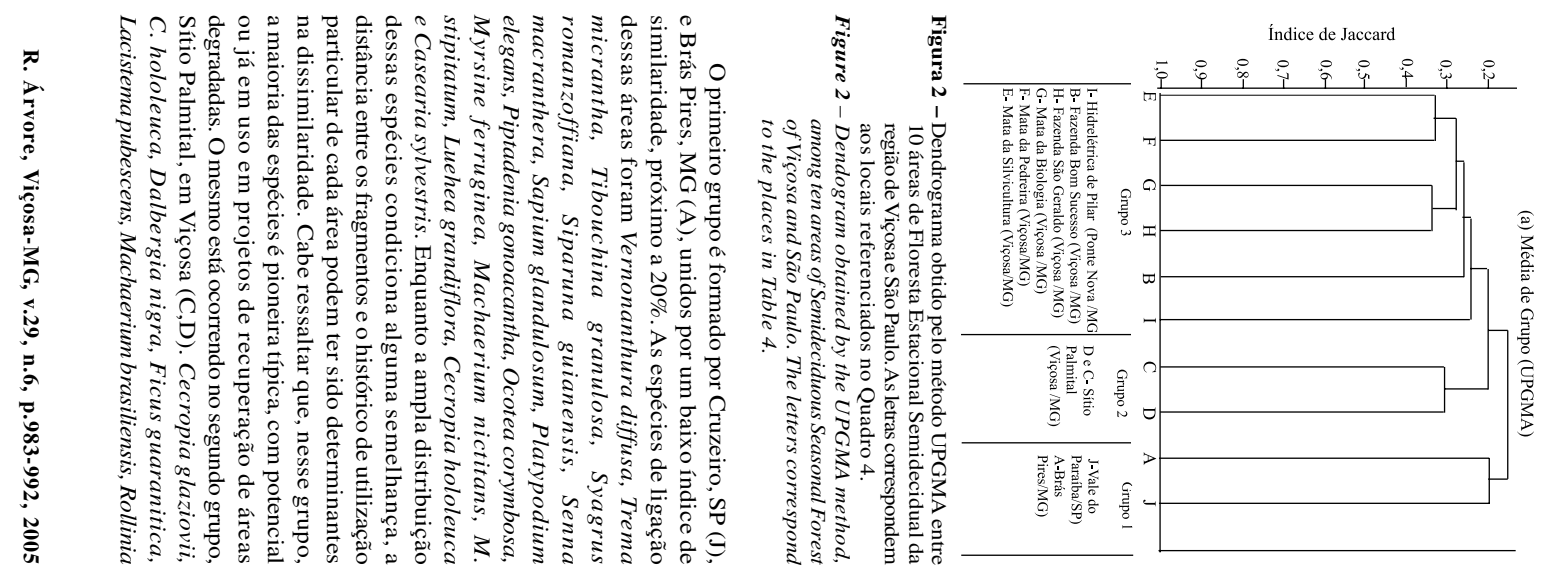
laurifolia, Siparuna guianensis, Vernonanthura diffusa, Sparattosperma leucanthum, Zanthoxylum rhoifolium e Xylopia sericea uniram essas áreas. O terceiro grupo, formado pelas áreas E, F, G, H, B e I, respectivamente, Mata da Silvicultura, Mata da Pedreira, Mata da Biologia, Fazenda São Geraldo, Fazenda Bom Sucesso, todas em Viçosa, MG, e Hidrelétrica de Pilar, em Ponte Nova, MG, caracteriza-se por florestas em estádio avançado de sucessão sem histórico recente de perturbação antrópica. Essas áreas mostram-se com uma tendência de se aproximarem da floresta mais primitiva (B), onde predominam espécies secundárias tardias, como Hortia arborea, Nectandra lanceolata e Ocotea odorifera.

As espécies Dalbergia nigra, Sparattosperma leucanthum e Zanthoxylum rhoifolium estiveram presentes em todas as áreas, formando a ligação entre elas. As espécies exclusivas encontradas neste estudo foram Brunfelsia brasiliensis, Cestrum coriaceum, Leandra niangaeformis, Ocotea cf. diospyrifolia, Ottonia propingua, Psidium rufum e Vismia magnoliaefolia. A ocorrência dessas espécies apenas na área do presente estudo destaca a importância da continuidade da conservação da área, através do seu isolamento de fatores de degradação, como fogo e gado.

\section{CONCLUSÕES}

A análise do substrato revelou o início de formação de um horizonte A, proveniente da incorporação de material orgânico via serapilheira depositada, condicionando uma melhora geral no "status" nutricional e facilitando o desenvolvimento de uma vegetação florestal.

A composição florística mostra uma floresta em transição da etapa seral pioneira para secundária inicial. No entanto, já apresenta elementos típicos das florestas em etapas serais mais avançadas - espécies secundárias tardias, indicando o avanço da sucessão secundária.

A síndrome de dispersão que prevalece é a zoocórica, possivelmente maximizada pela presença de indivíduos remanescentes na área atuando como poleiros, o que revela a importância da presença de fragmentos próximos como fonte de propágulos e o papel da fauna dispersora na recuperação de áreas degradadas.

As baixas similaridades com os fragmentos comparados foram condicionados ora pela distância entre eles, ora pelo estádio sucessional, bem como o histórico de uso particular de cada área.
Podem-se recomendar as espécies pioneiras e secundárias iniciais deste estudo na recomposição da vegetação florestal em áreas degradadas semelhantes.

\section{AGRADECIMENTOS}

À Fundação de Amparo à Pesquisa do Estado de Minas Gerais (FAPEMIG), pelo financiamento do projeto (EDT - 2186/2003) e ao Conselho Nacional de Desenvolvimento Científico e Tecnológico (CNPq), pela Bolsa de Produtividade em Pesquisa de Sebastião Venâncio Martins.

\section{REFERÊNCIAS BIBLIOGRÁFICAS}

ALVAREZ V, V.H. et al. Interpretação dos resultados das análises de solos. In: RIBEIRO, A C.; GUIMARÃES, P. T. G.; ALVAREZ,V. V. H.. (Eds.) Recomendações para uso de corretivos e fertilizantes em Minas Gerais. Viçosa, MG: CFSEMG, 1999. p. 25-32.

BARTH, R.C. Avaliação da recuperação de áreas mineradas no Brasil. Viçosa, MG: SIF, 1989. 41p. (Boletim Técnico, 1).

CAMPELLO, E.F.C. Sucessão vegetal na recuperação de áreas degradadas. In: DIAS, L.E.; MELLO. J,W. (Eds.). Recuperação de áreas degradadas. Viçosa, MG: UFV, SOBRADE, 1998. p.184-196.

CARMO, M.R.B.; MORELLATO, L.P.C. Fenologia de árvores e arbustos das matas ciliares da bacia do rio Tibagi, Estado do Paraná, Brasil. In: RODRIGUES, R. R.; LEITÃO-FILHO, H. F. (Eds.). Matas ciliares: conservação e recuperação. São Paulo: FAPESP, 2000. p. 125-141.

CONNELL, J.H.; SLATYER, R.O. Mechanisms of succession in natural communities and their role in community stability and organization. The Americam Naturalist, v.111, n.982, p. 1119-1144, 1977.

EMPRESA BRASILEIRA DE PESQUISA AGROPECUÁRIA - EMBRAPA. Centro Nacional de Pesquisas de Solos. Manual de métodos de análise de solo. Rio de Janeiro: 1999. 212p.

FRANCO, A.A. et al. Revegetação de solos degradados. Seropédica: EMBRAPA/CNPBA, 1992.9p. (Comunicado técnico, 9). 
GANDOLFI, S.; LEITÃO FILHO, H F.; BEZERRA, C.L.F. Levantamento florístico e caráter sucessional das espécies arbustivo-arbóreas de uma floresta semidecídua no município de Guarulhos, SP. Revista Brasileira de Biologia, v. 55, p.753-767, 1995.

GUEVARA, S.; PORATA, S.E.; DER MAAREL, E.V. The role of remnant forest trees in tropical secondary succession. Vegetation,v.66, p.77-84, 1986.

IRSIGLER, D.T. Composição florística e estrutura de um trecho primitivo de Floresta Estacional Semidecidual em Viçosa, MG. 2002. 64f. Dissertação (Mestrado em Botânica) - Universidade Federal de Viçosa, Viçosa, 2002.

JOHNSON, F.L.; GIBSON, D.J.; RISSER, P.G. Revegetation of unreclaimed coal strip-mines in Oklahoma. Journal of Applied Ecology, v.19, p. 453-463, 1982.

LEITÃO-FILHO, H.F. Aspectos taxonômicos das florestas do Estado de São Paulo. Silvicultura em São Paulo, v. 16, n. 1, p. 197-206, 1982.

LORENZO, J.S. Regeneração natural de uma área minerada de bauxita em Poços de Caldas, Minas Gerais. 1991. 151f. Dissertação (Mestrado em Ciência Florestal) - Universidade Federal de Viçosa, Viçosa, 1991.

LUGO, A.E. The apparent paradox of reestablishing species richness on degraded lands with tree monocultures. Forest Ecology and Management, v.99, p.9-19, 1997.

MARANGON, L.C.; SOARES, J.J.; FELICIANO, A.L. Florística arbórea da Mata da Pedreira, município de Viçosa, Minas Gerais. Revista Árvore, v.27, n.2, p.207-216, 2003.

MARTINS, S.V. et al. Colonization of gaps produced by death of bamboo clumbs in a Semideciduos Mesophytic Forest in Sout-eastern Brazil. Plant Ecology, v.172, p.121-131, 2004.

MARTINS, S.V.; RODRIGUES R.R. Gap-phase regeneration in Semideciduous Mesophytic Forest, south-eastern Brazil. Plant Ecology, v.163, p. 51-62, 2002.
MARTINS, S.V.;COUTINHO, M.P.; MARANGON, L.C. Composição florística e estrutura de uma floresta secundária no município de Cruzeiro, SP. Revista Árvore, v. 26, n. 1, p. 35-41, 2002.

MEDELLÍN, R.A.; GAONA, O. Seed dispersal by bats and birds in forest and disturbed habitats of Chiapas, México. Biotrópica, v.31, n.3, p.478-485, 1999.

MEIRA NETO, J.A.A.; MARTINS, F.R. Composição florística de uma floresta estacional semidecidual Montana no município de Viçosa-MG. Revista Árvore, v. 26, n. 4, p. 437-446, 2002.

MEIRA NETO, J.A.A. et al. Estrutura de uma floresta estacional semidecidual submontana em área diretamente afetada pela usina hidrelétrica de Pilar, Ponte Nova, Zona da Mata de Minas Gerais. Revista Árvore, v.21, n.3, p.338-344, 1997.

MORELLATO, L.P.C.; LEITÃO-FILHO, H.F. Padrões de frutificação e dispersão na Serra do Japi. In: MORELLATO, L.P.C. (Ed.). História Natural da Serra do Japi: Ecologia e preservação de uma área florestal no Sudeste do Brasil. Campinas: UNICAMP/ FAPESP, 1992. p. 112-140.

MUELLER-DOMBOIS, D.; ELLENBERG, H. Aims and methods of vegetation ecology. New York: John Wiley \& Sons. 1974. 547p.

NATALI, P.P.; VIANA, R.F.; FORTES, V.M. Proposta para recuperação ambiental da área de cava e adjacências da mineração de caulim na fazenda Boa Esperança, em Brás Pires - MG. In: SIMPÓSIO NACIONAL DE RECUPERAÇÃO DE ÁREAS DEGRADADAS, 3;1997, Ouro Preto. Anais... Viçosa, MG: UFV, 1997. p. 214-224.

OLIVEIRA-FILHO, A.T.; MACHADO, J.N.M. Composição florística e estrutura comunitária de um remanescente de floresta semidecídua montana, na serra de São José, Tiradentes, Minas Gerais, Acta Botânica Brasílica, v. 7 n. 2, p. $71-88,1993$.

R. Árvore, Viçosa-MG, v.29, n.6, p.983-992, 2005 
OLIVEIRA-FILHO, A.T.; SCOLFORO, J.R.S.; MELLO, J.M. Composição florística e estrutura comunitária de um remanescente de floresta semidecídua montana em Lavras, MG. Revista Brasileira de Botânica, v. 17, n. 2, p.167-182, 1994.

PARROTA, J.A.; KNOWLES, O.H.; WUNDERLEJR, J.M. Development of floristic diversity in 10-yearold restoration Forest on a bauxite mined site in Amazônia. Forest Ecology and Management, v.99, p.21-42, 1997.

PAULA, A. et al. Alterações florísticas ocorridas num período de quatorze anos na vegetação arbórea de uma floresta estacional semidecidual em ViçosaMG. Revista Árvore, v.26, n.6, p.743-749, 2002.

RIBAS, R.F. et al. Composição florística de dois trechos em diferentes etapas serais de uma floresta estacional semidecidual em Viçosa, Minas Gerais. Revista Árvore, v.27, n.6, p.821-830, 2003.

RODRIGUES, R.R.; GANDOLFI, S. Restauração de florestas tropicais: subsídios para uma definição metodológica e indicadores de avaliação e monitoramento. In: DIAS, L.E., MELLO. J,W. (Eds.). Recuperação de Áreas Degradadas. Viçosa, MG: UFV, SOBRADE, 1998. p.203-215.

RODRIGUES, R.R; MARTINS, S. V.; BARROS, L.C. Tropical Rain Forest regeneration in an area degraded by mining in Mato Grosso State, Brazil. Forest Ecology and Management, v.190, p.323-333, 2004.

RUIVO, M.L.P.; BARROS, N. F.; SCHAEFFER, C.E.R. Vegetação, biomassa microbiana e características do solo como indicadores de reabilitação de áreas mineradas na Amazônia Oriental, Belém. Revista de Ciências Agrárias, n.36, p.137-160, 2001.

R. Árvore, Viçosa-MG, v.29, n.6, p.983-992, 2005
SILVA, A. et al. Composição florística e grupos ecológicos das espécies de um trecho de floresta semidecídua submontana da Fazenda São Geraldo, Viçosa-MG. Revista Árvore, v.27, n.3, p.311-320, 2003.

TABARELLI, M.; VILLANI, J.P.; MANTOVANI, W. Estudo comparativo da vegetação de dois trechos de floresta secundária no Núcleo Santa Virgínia, Parque Estadual da Serra do Mar, SP. Revista do Instituto Florestal, v.6, p.1-11, 1994.

SHEPHERD, G. J. Fitopac 1, manual do usuário. Campinas: UNICAMP, 1996. 96p.

SKOUSEN, J.G.; JOHNSON, C.D.; GARBUTT, K. Natural revegetation of 15 abandoned mine land sites in west Virginia. Journal Environmental Quality, v. 23. p. 1224-1230, 1994.

TEIXEIRA, W.A.; FILHO, J.P.L. Fatores edáficos e a colonização de espécies lenhosas em uma cava de mineração de ferro em Itabirito, MG. Revista Árvore, v. 26, n.1, p. 25-33, 2002.

VALENTIM, J.L. Ecologia numérica: uma introdução à análise multivariada de dados. Rio de Janeiro: Interciências, 2000. 118p.

Van Der PIJL, P. Principles of dispersal in higher plants. 3.ed. Berlim: Springer-Verlag, 1982. 213p.

WUNDERLE Jr, J.M. The role of animal seed dispersal in accelerating native forest regeneration on degraded tropical lands. Forest Ecology and Management, v. 99, p. 233-235. 